Melanie R. Lovell and Meera Agar, HammondCare; Melanie R. Lovell and Frances M. Boyle, University of Sydney; Melanie R. Lovell, Tim Luckett, Jane Phillips, Meera Agar, and Patricia M. Davidson, ImPaCCT (New South Wales Palliative Care Trials Group); Tim Luckett and Patricia M. Davidson, University of Technology Sydney; Jane Phillips, University of Notre Dame; and Meera Agar, University of New South Wales, Sydney, New South Wales, Australia.

Published online ahead of print at www.jco.org on May 5, 2014.

Authors' disclosures of potential conflicts of interest and author contributions are found at the end of this article.

Corresponding author: Melanie R. Lovell, MBBS, PhD, FRACP, FAChPM, 97-115 River Rd, Greenwich NSW 2065, Australia; e-mail: mlovell@ hammond.com.au.

C 2014 by American Society of Clinical Oncology

0732-183X/14/3299-1/\$20.00

DOI: $10.1200 / J C O .2013 .52 .4850$

\title{
Patient Education, Coaching, and Self-Management for Cancer Pain
}

Melanie R. Lovell, Tim Luckett, Frances M. Boyle, Jane Phillips, Meera Agar, and Patricia M. Davidson

$$
\begin{array}{llllllll}
\text { A } & \text { B } & \text { S } & \text { T } & \text { R } & \text { A } & \text { C } & \text { T }
\end{array}
$$

\section{Purpose}

Multiple systematic reviews and meta-analyses have identified the effectiveness of patient education in improving cancer pain management. However, the mechanisms by which patient education improves pain outcomes are uncertain, as are the optimal delivery, content, timing, frequency, and duration. This review provides best-bet recommendations based on available evidence to guide service managers and clinicians in developing a patient education program.

\section{Methods}

We used patient-centered care, self-management, coaching, and a behavior change wheel as lenses through which to consider the evidence for elements of patient education most likely to be effective within the context of other strategies for overcoming barriers to cancer pain assessment and management.

\section{Results}

The evidence suggests that optimal strategies include those that are patient-centered and tailored to individual needs, are embedded within health professional-patient communication and therapeutic relationships, empower patients to self-manage and coordinate their care, and are routinely integrated into standard cancer care. An approach that integrates patient education with processes and systems to ensure implementation of key standards for pain assessment and management and education of health professionals has been shown to be most effective.

\section{Conclusion}

Patient education is effective in reducing cancer pain and should be standard practice in all settings. For optimal results, patient education should be integrated with other strategies for implementing evidence-based, person-centered care and overcoming barriers at the levels of patient, provider, and health system.

\section{J Clin Oncol 32. (c) 2014 by American Society of Clinical Oncology}

\section{INTRODUCTION}

There is a convincing body of evidence that patient education is effective in reducing pain intensity and (to a lesser degree) pain interference (Table 1). ${ }^{1-8}$ Indeed, patient education may be more effective than some coanalgesics ${ }^{6}$ and has negligible adverse effects. Not surprisingly, patient education is recommended by most clinical guidelines as a core component of management for all patients with cancer pain. $^{9-12}$

Unfortunately, however, the optimal delivery, content, timing, frequency, and duration of patient education are less clear. A large variety of approaches have been used with varying effect, and attempts by reviewers to understand the reasons for heterogeneity between results have so far been unsuccessful. Although it is clear that providing written information alone is insufficient for improving outcomes, there is no consistent evidence to help choose the optimal mode of delivery (eg, one to one $v$ group $v$ DVD), personnel (eg, nurse, physician, or peer advocate), or intensity (eg, one-off session $v$ repeat in-person follow-up visits $v$ telephone). The evidence also lacks consistency with regard to optimal content for patient education. Koller et $\mathrm{al}^{13}$ provide a comprehensive list of types of information included in patient educational interventions reported in the literature until 2010, highlighting the diversity of potential foci (Appendix Table A1, online only). Although intuitively, one might assume that more information is better, there is a danger of overwhelming patients, especially at clinical junctures associated with heightened distress such as diagnosis, start of treatment, and cancer recurrence. ${ }^{14}$ The field awaits definitive evidence on the best approach to use; however, this article provides clinicians with best-bet recommendations based on summation of the current body of relevant knowledge. 


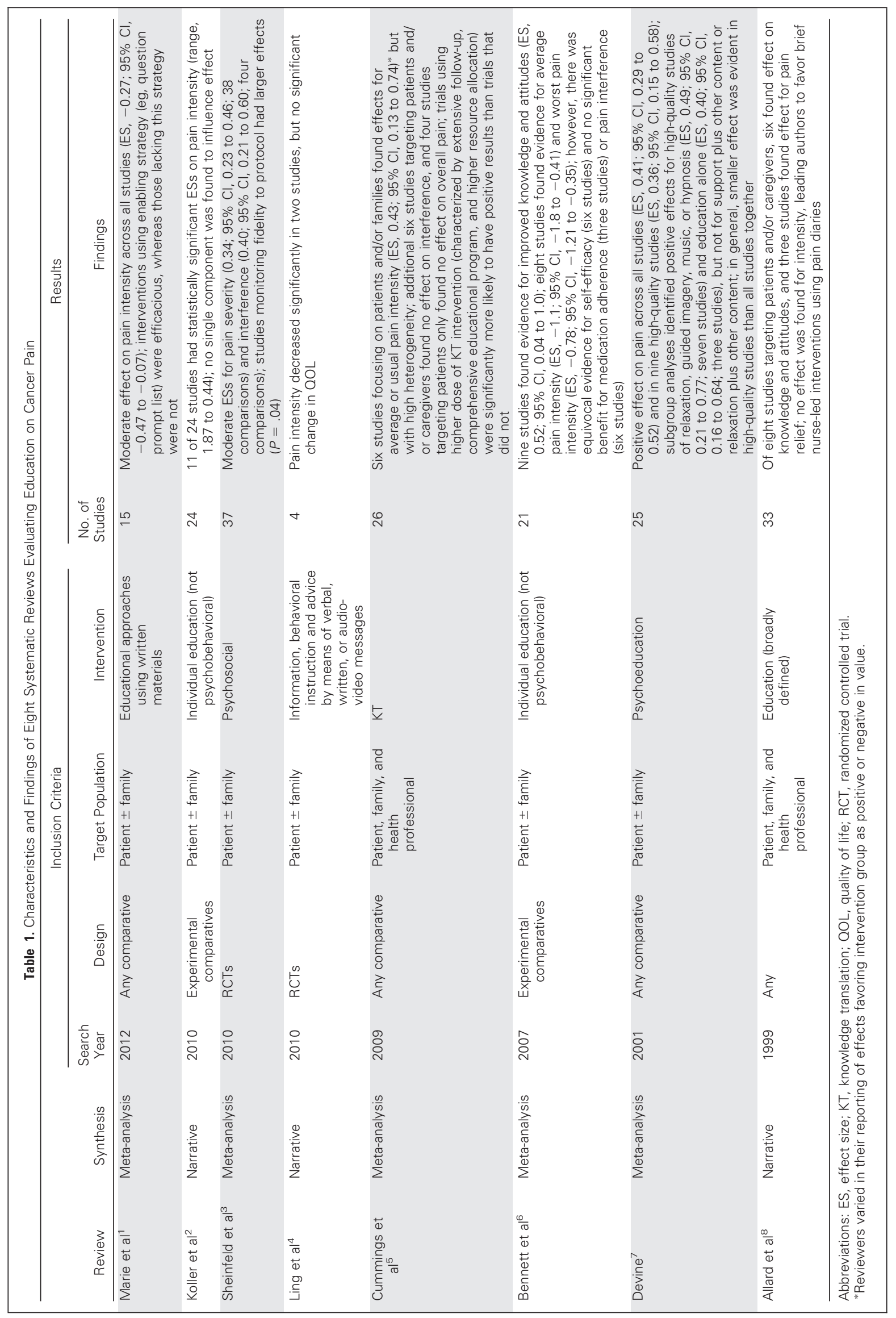




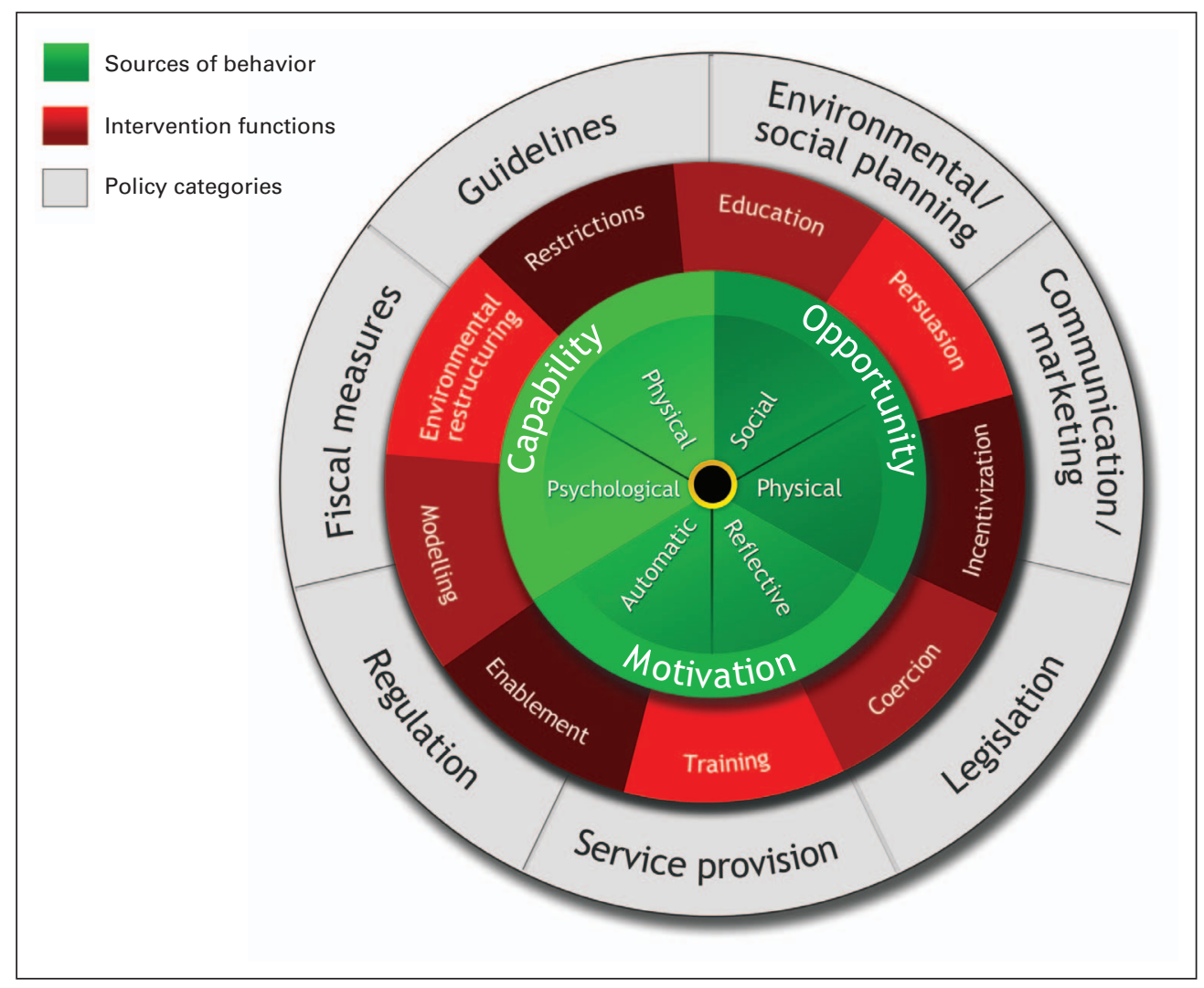

Fig 1. Behavior change wheel. Data adapted. ${ }^{17}$

\section{THEORETIC FRAMEWORK}

Our review goes beyond the confines of research explicitly pertaining to patient education to consider how this component of care might be strategically integrated with other system- and provider-level interventions to optimize assessment and management of cancer pain and overcome barriers to evidence-based, person-centered care. In so doing, we aim to move beyond the traditional model of education as knowledge transfer from clinician to patient and argue for its place instead as an essential component of the therapeutic relationship. In this model, information and resources are embedded in ongoing health professional-patient communication with the aim of empowering patients and family caregivers to confidently plan and manage their pain in partnership with the health care team.

Traditional cancer care is changing, as many individuals live longer and are cared for in a wider range of settings. ${ }^{9}$ Beyond the initial therapies for cancer, individuals are encouraged to incorporate a range of both pharmacologic and nonpharmacologic strategies into their self-management plans. This approach requires health professionals to partner with patients and their family caregivers to assist them in self-managing aspects of their health, including pain. Selfmanagement is a person-centered paradigm referring to a person's ability to manage the consequences of living with a chronic condition, including treatment, physical, social, and lifestyle changes. ${ }^{15}$ An essential element of effective self-management is building strong collaborative relationships between health professionals and patients and their family caregivers. ${ }^{16}$ Interventions for supporting self-management are well established for other chronic diseases like arthritis and diabetes, but they are relatively nascent for cancer.
Because improving pain management and self-management requires changes in behaviors by both clinicians and patients, we have also used behavior change wheel of Michie et $\mathrm{al}^{17}$ as a framework for interpreting relevant literature. Michie et al developed this taxonomy for describing and developing interventions to change health-related behaviors based on a comprehensive systematic review (Fig 1).

The framework posits that all behavioral change strategies work by affecting one or more of three essential conditions: capability, opportunity, and motivation. Education is one of nine functions that can mediate these impacts, each of which is influenced, in turn, by systemic and environmental factors such as policies and procedures. Patient education viewed through the behavior change wheel is a complex intervention that has multiple interacting components. ${ }^{18}$ The framework developed by Michie et $\mathrm{al}^{17}$ supports conceptualization of patient education as coaching rather than as a unidirectional transfer of knowledge from clinician to patient - an idea that is gaining ground in the cancer pain literature. ${ }^{19}$ Coaching facilitates behavioral change by identifying an individual's values and core strengths and transforming his or her goals into action using targeted and tailored strategies and support. ${ }^{20}$ By emphasizing patient-clinician partnership and patient empowerment, coaching has potential to bring about change through the functions of not only education but also persuasion, training, modeling, and enablement, thus offering a comprehensive patient-level intervention for improving pain assessment and management and overcoming barriers to person-centered evidence-based care. This article aims to highlight practical implications for patient education that arise from combining the complementary conceptual viewpoints of patient-centered care, self-management, coaching, and behavior change. 


\section{CORE PRINCIPLES}

We begin by highlighting four core principles that the evidence suggests should underpin any attempt at patient education relating to cancer pain.

\section{Principle 1: Pain Education, Assessment, and Management Should Be Person Centered}

The multidimensional and subjective nature of cancer pain means it is best thought of holistically as comprising physical, psychological, spiritual, and social factors, sometimes summarized as total pain. ${ }^{21}$ The experience, functional impact, and distress associated with pain and its management are all intensely personal and unique. $\mathrm{Pa}-$ tients are rightly considered experts on their own pain, and selfreporting is the gold standard in determining all pain dimensions. ${ }^{22}$ Successful management also depends on patient and caregiver engagement and adherence, in turn reliant on their experience, beliefs, attitudes, and motivations. In this sense, effective assessment and management of symptoms can be said to be driven and controlled by patients, with clinicians in a collaborative role. Qualitative studies highlight the need for an individualized, patient-led approach that enables management to be tailored to each patient's unique experience and changing preferences. ${ }^{23}$ For example, patients may prefer to live with low levels of pain rather than masking pain with medication, because they consider pain to be a useful means of monitoring tumor activity and health status. Equally, many patients will routinely vary their medication schedule to find an optimal balance between analgesia and adverse effects such as drowsiness in accordance with their planned activities. The health professional's role, therefore, in addition to assessment, diagnosis, and prescribing of appropriate treatment, is to maximize efficacy of self-management by patients and family caregivers by means of necessary information, resources, and support.

A management plan is developed based on goals identified by the patient with support from the medical team. Plans should enable patients to pace, balance, and prioritize their activities; to recognize and monitor the outer boundaries of self-management (eg, exercise intensity and analgesic titration); and to have the confidence and knowledge to mobilize the care or resources they require to manage their pain in a timely manner. ${ }^{24}$ An empowering approach to pain management ensures that patients are routinely provided with appropriate information tailored to their specific pain needs, have the skills to manage their analgesics and any adverse effects, and can identify the triggers for seeking additional medical or nursing support. Goals may be most useful if there are SMART - specific, measurable, achievable, relevant, and time-bound-goals (the Data Supplement provides some examples).

In terms of the behavior change wheel, a person-centered approach of this kind is likely to boost patients' motivation to change their behavior via the enablement function by focusing on what is personally important to them and giving them the confidence and means to foresee and overcome barriers.

\section{Principle 2: Patient Education Is an Integral Component of Health Professional-Patient Communication and Therapeutic Relationships}

People with cancer often attribute pain to disease progression. ${ }^{25}$ Patients sometimes feel fatalistic and powerless, to the extent they may even blame themselves for the pain. Communicating these meanings to health professionals often involves a disclosure of personal beliefs that is challenging but also therapeutic and formative in shaping care plans. It is essential that conversations about pain meaning be founded on respect for the patient so that they can lead to the establishment of trust. Trust will in turn allow the health professional to explain the possible causes and consequences of pain. Understanding the physiology of pain may reduce the fear associated with pain and, perhaps most importantly, confer a sense of control over what had previously seemed overwhelming. Hence, patient education has its roots in a trusting relationship between the patient and health professional. The patient, sensing the respect and care of the health professional, feels confidence that relief is possible and that the health professional is on the same team. Previously dominant and maladaptive ways of making sense of pain may be replaced with alternative ways of framing pain that render it responsive to action. In terms of the behavior change wheel, this process can be thought of as increasing motivation to control pain by persuasion and education. Motivational interviewing is a patient-centered technique using persuasion that has been consistently linked to positive behavioral change across health populations. $^{26,27}$ Motivational interviewing aims to increase intrinsic motivation by exploring and resolving ambivalence about behavioral change. An initial investigation of motivational interviewing for people with cancer pain found a trend toward improved effectiveness compared with education alone. ${ }^{28}$

\section{Principle 3: Patient Empowerment Is Essential}

Although direct evidence is lacking, there is circumstantial evidence that empowering patients may have beneficial effects on patient outcomes that are both direct and indirect. Improved sense of control was posited as a potential mechanism for pain relief by the authors of perhaps the most comprehensive review to date after they found that changes in patient attitudes and knowledge do not reliably translate into outcomes. ${ }^{6}$ As mentioned earlier, studies examining the experience of cancer pain have consistently found that loss of control is especially damaging to patients and difficult to cope with. Given the likely bidirectional relationship between pain and psychological distress and the fact that physical and existential pain cannot be separated easily, it seems likely that improving patients' sense of control may directly reduce the impact of pain, at least for some.

The importance of increasing patient control has since been supported by a systematic review and meta-analysis, which we undertook using the framework of Michie et $\mathrm{al}^{17}$ to explore heterogeneity among results from different interventions. ${ }^{1}$ This review found that enablement strategies that provided patients with the tools to increase capacity or opportunity for pain assessment and management have been especially efficacious in reducing pain intensity (Table 2).

It is impossible to determine whether reductions in pain were the result of an increase in patients' sense of control, improvements in pain reporting or self-management, or success in overcoming barriers such as fears about medication or suboptimal coordination between different providers. In the absence of definitive evidence, it seems sensible to adopt approaches to enablement that support all three mechanisms. Of particular value here are patient diaries and question prompt lists, many of which are freely available online (Appendix Table A2, online only). A sample pain management plan is provided in the Data Supplement, which not only provides patients and caregivers with information to support self-management but also offers a useful tool for informing health care providers. 


\begin{tabular}{|c|c|}
\hline Study & Enablement Strategy \\
\hline Arathuzik $^{29}$ & $\begin{array}{l}\text { Patients given advice on tailoring self-management according to pain experience (eg, "if you have mild pain, use } X \text {; if you have } \\
\text { moderate pain, use Y") }\end{array}$ \\
\hline Aubin et $a^{30}$ & $\begin{array}{l}\text { Question prompt sections about medications administration and dosage for use when requesting optimal adjustment; checklist for } \\
\text { adverse effects/events or schedule changes to support communication }\end{array}$ \\
\hline de Wit and van Dam ${ }^{31}$ & Pain diary, communication tool, and cassette with oral instruction to aid retention \\
\hline Yates et $\mathrm{al}^{32}$ & Personalized pain management plan, including strategies to address patient-specific barriers to effective pain management \\
\hline
\end{tabular}

An important implication of the imperative to empower patients is that health professionals may need to take the lead and encourage patients and caregivers to actively participate in decision making to prevent patients from otherwise naturally deferring to the clinical experts. ${ }^{33}$ Optimal pain management requires a patient-led approach, even for patients who prefer to defer to clinical experts for decisions about other aspects of health care. In terms of the behavior change wheel, empowering patients can be said to enhance opportunity and motivation via the functions of persuasion and enablement.

\section{Principle 4: Incorporating Patient Education As an Integral Part of Standard Care}

Despite the recommendations for routine patient education featured in numerous international guidelines, implementation remains variable. ${ }^{34}$ A number of factors influence implementation, including patients' receptiveness and available resources; health professionals' knowledge, attitudes, and beliefs; and policies, procedures, and other system variables that either support or deter, including patients as partners in care. Although various studies have demonstrated that short self-management courses led by peers or health professionals can be effective, sustained support provided in the context of ongoing cancer care may be the most efficient way of empowering patients to play a lead role in managing their pain. ${ }^{9}$ This approach also provides opportunities for the patient's care team, composed of cancer and primary care clinicians, to provide ongoing advice and support and to refine the patient's self-management plan in accordance with his or her needs and goals and the severity of pain. Effective communication between care team members minimizes the potential for fragmented care, which is perceived to be a key barrier to pain management by health professionals and patients alike. ${ }^{23,35}$ Incorporating patient education into standard care might be considered to improve opportunity and motivation by restructuring the clinical environment to one that promotes partnership and ensures care continues to be centered on the patient's needs over time.

INTEGRATING PATIENT EDUCATION INTO OTHER

EVIDENCE-BASED STRATEGIES FOR IMPROVING CANCER PAIN MANAGEMENT

\section{Patient-Held Clinical Pathway As a Tool for Patient Education}

Ensuring health professionals and patients are on the same page is critical in ensuring adherence to treatment recommendations, achieving optimal therapeutic outcomes, and avoiding adverse events. ${ }^{36}$ Clinical pathways that give step-by-step instructions to health professionals for standardized assessment and management have been associated more consistently with improvement in patient outcomes. ${ }^{37,38}$ Patient pathways that mirror health professional pathways and are endorsed as part of care may also have good potential to reduce ambiguities, enable monitoring of milestones (eg, schedules for pain management review), promote continuity of care, and facilitate person-centered care. Online pathways have also been adapted as strategies to promote participation in care. ${ }^{39}$

Although intuitively, patient-held records would seem to be advantageous in supporting communication and coordination of care, evidence is lacking in the case of cancer pain, and evaluations in the general health literature have had mixed results. ${ }^{40,41}$ The main challenges in implementation relate to generalizability across patient groups and the lack of agreement between patients and health professionals regarding the role of such records. Future efforts should be targeted at optimizing use of patient-held records, as supportive information technology becomes increasingly available and affordable and mobile devices become ever more common among people with cancer. In terms of the behavior change wheel, a patient-held clinical pathway and record might have an impact on all three conditions via the functions of education, training, and enablement.

\section{Educating and Training Health Professionals to Routinely Provide Self-Management Strategies}

Helping clinicians develop the capacity to increase patient adoption of recommended treatment and symptom control strategies is essential to improving pain management. ${ }^{28}$ However, few clinicians have been formally taught how to educate and empower patients to manage themselves. This approach may seem counterintuitive to clinicians accustomed to the role of expert in physician-patient interactions. Kaiser Permanente in the United States is one organization that formally teaches its clinicians a patient-centered approach to conversations, including providing patient education. To increase patients' adherence to recommended treatments and to effect positive outcomes, clinicians are asked to choose one or two key points to emphasize during any one visit, to use plain language (as in the vignette provided later in this article), and to get the patient to "teach back" to demonstrate that the content has been understood. ${ }^{42}$ Oral content is supplemented with written material, such as an after-visit summary, memory aids, or links to relevant Web sites. ${ }^{43}$ Before closing the discussion, the clinician is asked to outline to the patient the planned next steps. ${ }^{44}$

Qstream (formally Spaced Education) is an approach to health professional education that offers potential for providing training in patient education to a wide audience of clinicians. ${ }^{45}$ Qstream is an 


\begin{tabular}{|c|c|c|c|}
\hline \multirow{2}{*}{$\begin{array}{l}\text { Behavioral Change Function and } \\
\text { Definition }\end{array}$} & \multicolumn{3}{|c|}{ Example of Strategies for Overcoming Barriers to Cancer Pain Assessment and Management (level) } \\
\hline & Patient & Health Professional & System \\
\hline $\begin{array}{l}\text { Education (increasing knowledge or } \\
\text { understanding) }\end{array}$ & $\begin{array}{l}\text { Information on types of pain, medication, } \\
\text { and adverse effects (especially low } \\
\text { risk of opioid addiction) and when and } \\
\text { from whom to seek help }\end{array}$ & $\begin{array}{l}\text { Information on opioid dosage, conversion, } \\
\text { and use in patients who are older and/ } \\
\text { or have renal failure }\end{array}$ & $\begin{array}{l}\text { Data on prevalence of cancer } \\
\text { pain }\end{array}$ \\
\hline $\begin{array}{l}\text { Incentivization (creating expectation } \\
\text { of reward) or coercion (creating } \\
\text { expectation of punishment or } \\
\text { cost) }\end{array}$ & $\begin{array}{l}\text { Patient pain diary aimed at elucidating } \\
\text { factors exacerbating and alleviating } \\
\text { pain and consequences for daily life }\end{array}$ & \multicolumn{2}{|c|}{$\begin{array}{l}\text { Audit and feedback regarding pain assessment, management, and } \\
\text { outcomes; national benchmarking (eg, Palliative Care Outcomes } \\
\text { Collaboration }{ }^{48} \text { ) }\end{array}$} \\
\hline Training (imparting skills) & $\begin{array}{l}\text { Reliable use of numeric rating scale to } \\
\text { rate pain severity; self-management } \\
\text { (eg, storage and administration of } \\
\text { medications) }\end{array}$ & $\begin{array}{l}\text { Undertaking of comprehensive } \\
\text { assessment; evaluation of risk of opioid } \\
\text { misuse; safe prescribing of opiates; } \\
\text { education of patients }\end{array}$ & $\begin{array}{l}\text { Implementation of routine } \\
\text { screening for pain }\end{array}$ \\
\hline $\begin{array}{l}\text { Environmental restructuring } \\
\text { (changing physical or social } \\
\text { context) }\end{array}$ & $\begin{array}{l}\text { Involving caregivers and family to } \\
\text { encourage reporting of pain and } \\
\text { provide appropriate support }\end{array}$ & Clinical pathways & \\
\hline $\begin{array}{l}\text { Modeling (providing example for } \\
\text { people to aspire to or imitate) }\end{array}$ & $\begin{array}{l}\text { Providing patients with personal stories } \\
\text { (eg, via DVD) of others who have } \\
\text { successfully self-managed their pain }\end{array}$ & $\begin{array}{l}\text { Presentations and grand rounds by expert } \\
\text { clinicians }\end{array}$ & Centers of excellence \\
\hline $\begin{array}{l}\text { Enablement (increasing means or } \\
\text { reducing barriers to increase } \\
\text { capability or opportunity) }\end{array}$ & \multicolumn{2}{|c|}{$\begin{array}{l}\text { Goal setting and question prompt list to support communication between patient and } \\
\text { medical team }\end{array}$} & $\begin{array}{l}\text { Patient-held records to improve } \\
\text { communication between } \\
\text { providers and coordination of } \\
\text { care }\end{array}$ \\
\hline
\end{tabular}

NOTE. Data adapted. ${ }^{17}$

Abbreviation: CBT, cognitive behavioral therapy.

online platform based on the observations that spacing and repeating learning content, which is later tested, provide a more effective learning format than bolus distribution. In randomized controlled studies, Qstream has been shown to improve knowledge acquisition and retention and have a positive impact on clinical practice. ${ }^{45-47}$ The online learning format of Qstream is designed to deliver evidence-based learning content to busy clinicians in brief installments rather than requiring substantial time commitments at training sessions. These qualities make Qstream ideal for training health professionals on how to empower and educate their patients to effectively self-manage their pain. In terms of the behavioral change wheel, health professional education and training have the potential to affect all three conditions for changing clinician behavior, with flow-on effects to changing patient behavior in the ways already described.

A summary of all these elements as they might be viewed through the lens of the behavior change wheel of Michie et $\mathrm{al}^{17}$ is presented in Table 3. An example of how these recommendations might be implemented in the case of an individual patient is presented in the textbox vignette.

\section{HEALTH SERVICE ISSUES RELEVANT TO PATIENT EDUCATION ON CANCER PAIN}

Improving patient education often requires a reconfiguration of the health care setting to be more focused on the needs of the individual patient rather than the health care organization. A report from the Institute of Medicine in the United States has called for improvements to services in terms of their safety, effectiveness, patient centeredness, timeliness, and equity of access.

These factors provide a useful blueprint for formulating strategies to improve cancer pain management. Beyond providing information to patients, inbuilt monitoring processes are needed to ensure that care is tailored to meet the needs of the individual, accessible, and regularly reviewed to avoid adverse events. For example, monitoring the introduction of opioids, starting slowly and titrating according to adverse effects and efficacy, is likely to promote treatment adherence and avoid adverse drug reactions. This Institute of Medicine report emphasizes that as health professionals, we have to consider our clinical decisions within the context of the best available evidence; within the knowledge, attitudes, and beliefs of the individual and his or her family; and within the broader context of the health care system. Ensuring that patients who live at a distance from expert pain management settings have access to the best available treatments can be addressed by strategies such as telehealth. ${ }^{49}$ However, perhaps what is most critical is ensuring that patients have a powerful voice in decision making and care planning. ${ }^{50,51}$

The literature suggests that education needs may vary at the population level as well as among different individuals. A study conducted at the MD Anderson Cancer Center (Houston, TX) found patients attending its palliative care service to show remarkable 
Mrs S, a 67-year-old woman with metastatic breast cancer involving bones and lungs, attended her oncology clinic for a routine chemotherapy appointment accompanied by her husband. She was noted to be limping as she walked in and sat uncomfortably in the treatment chair, appearing distracted and anxious. When questioned by the treating nurses, Mrs S admitted to a sudden increase in pain in her groin, which was aching in character and had increased with movement over the preceding weekend. Her maintenance analgesia of low-dose long-acting opioids had not provided sufficient relief, and she had been unable to sleep or shower independently. She had taken some breakthrough short-acting opioid but became nauseated, drowsy, and constipated. Her husband was worried about her getting dependent on strong analgesia and discouraged her from taking more. No contact with medical services had been made, because she was concerned that health professionals would consider the pain a sign that the chemotherapy was not working and stop treatment. Medical review, triggered by the nursing staff, identified a pathologic fracture of her inferior pubic ramus and hypercalcemia. Admission for management was arranged. An oncology nurse interviewed Mrs S and her husband to develop a detailed case history and understand the meaning they attached to pain within the context of other health beliefs and concerns as well as insight into their relationship (including any caregiving role adopted by $\mathrm{Mr}$ S) and Mrs S's psychosocial and cognitive functioning. Personal goals for pain management were established in accordance with Mrs S's priorities regarding her role in family life and traveling to chemotherapy. Mrs S was trained in using a diary to identify changes in intensity, type, or location and to distinguish between possible causes. The diary was personalized with information about Mrs S's prescriptions, including when to take each medication; potential adverse effects and how to manage these; and what to do if pain persisted, including suggestions for whom to contact as well as breakthrough medication. Information was given to reassure Mrs S and her husband about the rareness of addiction to opioids in a person with no previous history of addiction; this was explained within the context of a discussion about the difference between addiction, dependence, and tolerance. Mrs S was referred to a counselor for more comprehensive assessment and ideas on strategies to cope with feelings of anxiety. Finally, Mr and Mrs S were given a telephone number to call if they thought of questions after the interview and were encouraged to communicate with their multidisciplinary team on a regular basis. Throughout, the interview took a coaching approach, in which the positive capabilities of Mrs S and her family to self-manage pain were highlighted while also emphasizing the supports available via a range of services. opioid-related knowledge and adherence and few patient-level barriers as measured by Ward's barriers questionnaire. ${ }^{52,53}$ More research is needed to identify whether palliative care patients are generally more adherent than oncology patients or whether this finding was a factor of the study site being a center of excellence; unfortunately, the authors provided no information about their patient education program. This study is among several to find a difference in patient-level barriers to cancer pain management among patients of different cultural backgrounds, which suggests that health-related beliefs and associated barriers may vary consistently enough for programs to offer special initiatives based on the sociodemographic characteristics of the population served. ${ }^{54}$

Cancer services that serve populations with low health literacy will also need a modified approach to patient education. Health literacy is a complex construct describing an individual's capacity to learn information pertaining to his or her health and apply it to his or her self-care regimen. ${ }^{55}$ A recent systematic review identified 17 separate definitions and 12 health literacy conceptual models, exemplifying the complexity of this construct. ${ }^{56}$ The defining key features of these various definitions included capacity to communicate with health professionals, adherence to treatment, and navigation of the health care system. Elements relevant to pain education include verbal literacy, print literacy, and numeracy (eg, ability to understand that dosing of $2 \mathrm{~mL}$ of a $5 \mathrm{mg} / \mathrm{mL}$ mixture is the same as $10 \mathrm{mg}$ ). People at risk of low health literacy include the elderly, those who do not speak the dominant language, those with lower levels of education, and those with lower socioeconomic status - factors also associated with poorer pain control. In terms of the behavioral change framework, those with low health literacy can be said to have reduced capability and opportunity and may thus benefit from more intensive interventions targeting enablement and training. Demonstration techniques and visual approaches (eg, DVDs) may be especially useful. Addressing health literacy is central to improving pain outcomes, requiring a commitment by health professionals to partner with patients, acquire the knowledge and resources to access health literacy using valid and reliable measures, ${ }^{57}$ and have the capacity to tailor information and resources according to patients' literacy and educational needs. ${ }^{55}$

Patients with substance abuse disorders and their health care clinicians may also have specific educational needs that warrant tailored programs, especially by services with a substantial proportion of patients in this group. An increasing number of people experiencing cancer pain may have a history of substance misuse or may use analgesia to treat emotional distress. People with inadequate analgesia may be seen as drug seeking. ${ }^{58}$ Asking questions to determine the prevalence of aberrant behaviors and attitudes was not found to be offensive in a group of patients with cancer. ${ }^{59}$ The therapeutic alliance we have described in this article is especially important in this group of patients to have confidence that pain can be relieved and some control over the substance abuse disorder can be achieved. ${ }^{60}$

\section{IMPLICATIONS FOR RESEARCH}

There are many unanswered questions about improving patient education. Additional research on how education mediates improvements in pain control is needed, ideally using theory-based approaches that test specific hypotheses. In addition to examining how knowledge and skills may influence pain, more research is needed 
on how patient attitudes and self-efficacy may cause or mediate effects on pain, anxiety, coping, and well-being. There is also a need to test complex interventions that integrate patient education with other strategies for improving cancer pain assessment and management and overcoming barriers at the levels of health provider and health system as well as patient. Such attempts should use a cohesive theoretic framework and be evaluated using research designs that offer potential to understand interactions among different components and relationships between processes and outcomes. ${ }^{18}$ To drive implementation of evidence-based practice, a challenge for the future is the incorporation of effective patient education within health care standards, thereby incentivizing uptake and positioning it as integral parts of patient care.

To ensure knowledge can be built cumulatively, it would be helpful if educational elements and outcome measures could be standardized in future trials. Education materials for which there is evidence of effectiveness should be made available on the Internet, as called for by other authors. ${ }^{61}$ These materials can then be adapted to meet the needs of specific cultural groups, tumor groups, and clinical settings. ${ }^{62}$

\section{DISCUSSION}

This review highlights the importance of patient education as a key part of the cancer pain management puzzle. The process of patient education is dynamic and interactive, not a static passive process. To provide education effectively, clinicians need to be aware of both the internal and external resources of each individual and consider his or her sociocultural context. No longer is effective pain management solely to be thought of as administration of pharmacologic and nonpharmacologic treatments. Increasingly, health professionals partner with patients and their caregivers in a range of care settings using a library of resources. Peak professional bodies, consumer groups, and government agencies each play a critical role in ensuring that education strategies for cancer pain management are evidence based, patient centered, and widely implemented. Using a framework for behavioral change at patient, provider, and health system levels can inform interventions and their ongoing development and adaptation by providing a coherent and cohesive approach to constructing the evidence base.

\section{AUTHORS' DISCLOSURES OF POTENTIAL CONFLICTS} OF INTEREST

The author(s) indicated no potential conflicts of interest.

\section{AUTHOR CONTRIBUTIONS}

Conception and design: All authors

Collection and assembly of data: Tim Luckett

Data analysis and interpretation: All authors

Manuscript writing: All authors

Final approval of manuscript: All authors

\section{REFERENCES}

1. Marie $N$, Luckett $T$, Davidson PM, et al: Optimal patient education for cancer pain: A systematic review and theory-based meta-analysis. Support Care Cancer 21:3529-3537, 2013

2. Koller A, Miaskowski C, De Geest S, et al: Supporting self-management of pain in cancer patients: Methods and lessons learned from a randomized controlled pilot study. Eur J Oncol Nurs 17:1-8, 2013

3. Sheinfeld Gorin S, Krebs P, Badr H, et al: Meta-analysis of psychosocial interventions to reduce pain in patients with cancer. J Clin Oncol 30:539-547, 2012

4. Ling CC, Lui LY, So WK: Do educational interventions improve cancer patients' quality of life and reduce pain intensity? Quantitative systematic review. J Adv Nurs 68:511-520, 2012

5. Cummings GG, Olivo SA, Biondo PD, et al: Effectiveness of knowledge translation interventions to improve cancer pain management. J Pain Symptom Manage 41:915-939, 2011

6. Bennett MI, Bagnall AM, José Closs S: How effective are patient-based educational interventions in the management of cancer pain? Systematic review and meta-analysis. Pain 143:192-199, 2009

7. Devine EC: Meta-analysis of the effect of psychoeducational interventions on pain in adults with cancer. Oncol Nurs Forum 30:75-89, 2003

8. Allard $P$, Maunsell E, Labbé J, et al: Educational interventions to improve cancer pain control: A systematic review. J Palliat Med 4:191-203, 2001

9. McCorkle R, Ercolano E, Lazenby M, et al: Self-management: Enabling and empowering patients living with cancer as a chronic illness. CA Cancer J Clin 61:50-62, 2011
10. National Comprehensive Cancer Network: NCCN Clinical Practice Guidelines in Oncology: Adult cancer pain, 2010. http://www.nccn.org/professionals/ physician_gls/f_guidelines.asp

11. NICE Clinical Guideline 140: Opioids in Palliative Care: Safe and Effective Prescribing of Strong Opioids for Pain in Palliative Care of Adults. London, United Kingdom, NICE, 2012

12. Caraceni A, Hanks G, Kaasa S, et al: Use of opioid analgesics in the treatment of cancer pain: Evidence-based recommendations from the EAPC. Lancet Oncol 13:e58-e68, 2012

13. Koller A, Miaskowski $C$, De Geest $S$, et al: A systematic evaluation of content, structure, and efficacy of interventions to improve patients' selfmanagement of cancer pain. J Pain Symptom Manage 44:264-284, 2012

14. Ziegler L, Hill K, Neilly L, et al: Identifying psychological distress at key stages of the cancer illness trajectory: A systematic review of validated self-report measures. J Pain Symptom Manage 41: 619-636, 2011

15. Barlow J, Wright C, Sheasby J, et al: Selfmanagement approaches for people with chronic conditions: A review. Patient Educ Couns 48:177187, 2002

16. World Health Organization: Innovative Care for Chronic Conditions: Building Blocks for Action. Geneva, Switzerland, World Health Organization, 2002

17. Michie $S$, van Stralen MM, West $R$ : The behaviour change wheel: A new method for characterising and designing behaviour change interventions. Implement Sci 6:42, 2011

18. Craig $P$, Dieppe $P$, Macintyre $S$, et al: Developing and evaluating complex interventions: The new Medical Research Council guidance. Int J Nurs Stud 50:587-592, 2013
19. Kravitz RL, Tancredi DJ, Grennan $T$, et al: Cancer Health Empowerment for Living without Pain (Ca-HELP): Effects of a tailored education and coaching intervention on pain and impairment. Pain 152:1572-1582, 2011

20. Street RL Jr, Slee C, Kalauokalani DK, et al: Improving physician-patient communication about cancer pain with a tailored education-coaching intervention. Patient Educ Couns 80:42-47, 2010

21. Saunders $C$ : The Philosophy of Terminal Care. Baltimore, MD, Arnold Publishers, 1984, pp 232-241

22. Bodenheimer $T$, Lorig $K$, Holman $H$, et al: Patient self-management of chronic disease in primary care. JAMA 288:2469-2475, 2002

23. Luckett $T$, Davidson PM, Green $A$, et al: Assessment and management of adult cancer pain: A systematic review and synthesis of recent qualitative studies aimed at developing insights for managing barriers and optimizing facilitators within a comprehensive framework of patient care. J Pain Symptom Manage 46:229-253, 2013

24. Kralik D, Koch $T$, Price $K$, et al: Chronic illness self-management: Taking action to create order. J Clin Nurs 13:259-267, 2004

25. Flemming $\mathrm{K}$ : The use of morphine to treat cancer-related pain: A synthesis of quantitative and qualitative research. J Pain Symptom Manage 39: 139-154, 2010

26. Lundahl B, Burke BL: The effectiveness and applicability of motivational interviewing: A practicefriendly review of four meta-analyses. J Clin Psychol 65:1232-1245, 2009

27. Miller WR, Rollnick S: Motivational Interviewing: Preparing People for Change (ed 2). New York, NY, Guilford Press, 2002

28. Thomas ML, Elliott JE, Rao SM, et al: A randomized, clinical trial of education or motivationalinterviewing-based coaching compared to usual care to 
improve cancer pain management. Oncol Nurs Forum 39:39-49, 2012

29. Arathuzik D: Effects of cognitive-behavioural strategies on pain in cancer patients. Cancer Nurs 17:207-214, 1994

30. Aubin M, Vézina $L$, Parent $R$, et al: Impact of an educational program on pain management in patients with cancer living at home. Oncol Nurs Forum 33:1183-1188, 2006

31. de Wit R, van Dam F: From hospital to home care: A randomized controlled trial of a pain education programme for cancer patients with chronic pain. J Adv Nurs 36:742-754, 2001

32. Yates $P$, Edwards $E$, Nash $R$, et al: A randomized controlled trial of a nurse-administered educational intervention for improving cancer pain management in ambulatory settings. Patient Educ Couns 53:227-237, 2004

33. Kiesler DJ, Auerbach SM: Optimal matches of patient preferences for information, decisionmaking and interpersonal behavior: Evidence, models and interventions. Patient Educ Couns 61: 319-341, 2006

34. Green E, Zwaal C, Beals C, et al: Cancerrelated pain management: $A$ report of evidencebased recommendations to guide practice. Clin J Pain 26:449-462, 2010

35. Lovell M, Agar M, Luckett T, et al: Australian survey of current practice and guideline use in adult cancer pain assessment and management: Perspectives of palliative care physicians. J Palliat Med 16:1403-1409, 2013

36. Lewin S, Skea Z, Entwistle V, et al: Interventions for providers to promote a patient-centered approach in clinical consultations. Cochrane Database Syst Rev 4:CD003267, 2001

37. Brink-Huis $A$, van Achterberg $T$, Schoonhoven $L$, et al: Pain management: A review of organisation models with integrated processes for the management of pain in adult cancer patients. J Clin Nurs 17:1986-2000, 2008

38. Rotter $T$, Kinsman $L$, James $E$, et al: Clinical pathways: Effects on professional practice, patient outcomes, length of stay and hospital costs. Cochrane Database Syst Rev 3:CD006632, 2010

39. Ryhänen AM, Rankinen $S$, Tulus $K$, et al: Internet based patient pathway as an educational tool for breast cancer patients. Int J Med Inform 81:270-278, 2012

40. Gysels M, Richardson A, Higginson IJ: Does the patient-held record improve continuity and related outcomes in cancer care: A systematic review. Health Expect 10:75-91, 2007

41. Ko $H$, Turner $T$, Jones $C$, et al: Patient-held medical records for patients with chronic disease: $A$ systematic review. Qual Saf Health Care 19:e41, 2010

42. Grueninger UJ, Duffy D, Goldstein MG: Patient education in the medical encounter: How to facilitate learning, behavior change, and coping, in Lipkin MJ, Putnam SM, Lazare A (eds): The Medical Interview: Clinical Care, Education, and Research. New York, NY, Springer-Verlag, 1995, pp 122-133

43. Farmer $A P$, Légaré $T$, Turcot $L$, et al: Printed educational materials: Effect on professional practice and health care outcomes. Cochrane Database Syst Rev 3:CD004398, 2008

44. Frankel RM, Stein T: Getting the most out of the clinical encounter: The four habits model. J Med Pract Manage 16:184-191, 2001

45. Kerfoot BP: Adaptive spaced education improves learning efficiency: A randomized controlled trial. J Urol 183:678-681, 2010

46. Kerfoot BP, Fu $Y$, Baker $\mathrm{H}$, et al: Online spaced education generates transfer and improves long-term retention of diagnostic skills: A randomized controlled trial. J Am Coll Surg 211:331.e1337.e1, 2010

47. Kerfoot BP, Lawler EV, Sokolovskaya G, et al: Durable improvements in prostate cancer screening from online spaced education a randomized controlled trial. Am J Prev Med 39:472-478, 2010

48. Eagar $K$, Watters $P$, Currow DC, et al: The Australian Palliative Care Outcomes Collaboration (PCOC): Measuring the quality and outcomes of palliative care on a routine basis. Aust Health Rev 34:186-192, 2010

49. McGeary DD, McGeary CA, Gatchel RJ: A comprehensive review of telehealth for pain management: Where we are and the way ahead. Pain Pract 12:570-577, 2012

50. Charles C, Gafni A, Whelan T: Shared decision-making in the medical encounter: What does it mean? (or it takes at least two to tango). Soc Sci Med 44:681-692, 1997

51. Thorne S, Oliffe JL, Stajduhar KI: Communicating shared decision-making: Cancer patient perspectives. Patient Educ Couns 90:291-296, 2013

52. Nguyen LM, Rhondali W, De la Cruz M, et al: Frequency and predictors of patient deviation from prescribed opioids and barriers to opioid pain management in patients with advanced cancer. J Pain Symptom Manage 45:506-516, 2013

53. Ward SE, Goldberg N, Miller-McCauley V, et al: Patient-related barriers to management of cancer pain. Pain 52:319-324, 1993

54. Chen $\mathrm{CH}$, Tang ST, Chen $\mathrm{CH}$ : Meta-analysis of cultural differences in Western and Asian patientperceived barriers to managing cancer pain. Palliat Med 26:206-221, 2012

55. Westlake C, Sethares K, Davidson P: How can health literacy influence outcomes in heart failure patients? Mechanisms and interventions. Curr Heart Fail Rep 10:232-243, 2013

56. Sørensen K, Van den Brouke S, Fullam J, et al: Health literacy and public health: A systematic review and integration of definitions and models. BMC Public Health 12:80, 2012

57. Speros C: Health literacy: Concept analysis. J Adv Nurs 50:633-640, 2005

58. Childers JW, Arnold RM: "I feel uncomfortable 'calling a patient out'": Educational needs of palliative medicine fellows in managing opioid misuse. J Pain Symptom Manage 43:253-260, 2012

59. Passik SD, Kirsh KL, McDonald MV, et al: A pilot survey of aberrant drug-taking attitudes and behaviors in samples of cancer and AIDS patients. $J$ Pain Symptom Manage 19:274-286, 2000

60. Passik SD, Theobald DE: Managing addiction in advanced cancer patients: Why bother? J Pain Symptom Manage 19:229-234, 2000

61. Stiles CR, Biondo PD, Cummings G, et al: Clinical trials focusing on cancer pain educational interventions: Core components to include during planning and reporting. J Pain Symptom Manage 40:301-308, 2010

62. Meghani SH, Polomano RC, Tait RC, et al: Advancing a national agenda to eliminate disparities in pain care: Directions for health policy, education, practice, and research. Pain Med 13:5-28, 2012 


\section{Appendix}

Table A1. Information Commonly Included in Patient Educational Interventions

Information

Causes of pain in people with cancer

Common pain experiences (eg, onset, timing, quality, severity)

Effective treatments (pharmacologic and nonpharmacologic)

Attitudes and beliefs that may pose barriers to effective pain control (eg, fear that opioids are addictive)

Adverse effects of analgesias

Safety concerns (eg, mixing with alcohol, driving)

How to communicate and work in partnership with health professionals to achieve pain control (eg, importance of reporting rather than concealing pain, adverse effects and other concerns about medication)

Ways to ensure adequate access to medicines

NOTE. Data adapted. ${ }^{13}$

Table A2. Selected Pain Diary Templates and Other Patient Resources Available Online at No Cost-Online Only

\begin{tabular}{|c|c|}
\hline Source & Link \\
\hline American Cancer Society & $\begin{array}{l}\text { http://www.cancer.org/acs/groups/content/@editorial/documents/document/acspc-033203.pdf } \\
\text { http://www.cancer.org/acs/groups/cid/@nho/documents/webcontent/pain-diary.pdf }\end{array}$ \\
\hline American Chronic Pain Association & http://www.theacpa.org/uploads/Pain\%20Log\%20Rev\%202010-V2.pdf \\
\hline $\begin{array}{l}\text { American Geriatrics Society } \\
\text { Foundation for Health in Ageing }\end{array}$ & $\begin{array}{l}\text { http://www.healthinaging.org/aging-and-health-a-to-z/topic:pain- } \\
\text { management/resource:tools-and-tips/ }\end{array}$ \\
\hline American Pain Foundation & http://www.partnersagainstpain.com/printouts/Daily_Pain_Diary.pdf \\
\hline $\begin{array}{l}\text { American Society of Clinical } \\
\text { Oncology }\end{array}$ & $\begin{array}{l}\text { http://store2.asco.org/ASCO-Answers-Storage-Disposal-Medications/dp/B00BI4QBFA?field_availability=-1 } \\
\text { \&field_browse=5285085011\&field_product_site_launch_date_utc=-1y\&id=ASCO+Answers+ } \\
\text { Storage+Disposal+Medications\&ie=UTF8\&refinementHistory=subjectbin \%2Ccolor_map } \% 2 \\
\text { Cprice\%2Csize_name\%2Cauthor-bin\&searchNodeID=5285085011\&searchPage =1\& } \\
\text { searchRank=salesrank\&searchSize }=12\end{array}$ \\
\hline $\begin{array}{l}\text { Australian Pain Management } \\
\text { Association }\end{array}$ & http://www.painmanagement.org.au/self-help \\
\hline Breast Cancer Research Foundation & $\begin{array}{l}\text { http://healthology.com/pap/A7012PD4.pdf } \\
\text { http://healthology.com/pap/A7012PD6.pdf }\end{array}$ \\
\hline Canadian Pain Coalition & http://www.canadianpaincoalition.ca/media/pain_diary.pdf \\
\hline Cancer Council New South Wales & $\begin{array}{l}\text { http://www.cancercouncil.com.au/620/b1000/overcoming-cancer-pain-44/describing- } \\
\text { pain-and-discomfort/?pp_=\%20620 }\end{array}$ \\
\hline Change Pain & $\begin{array}{l}\text { http://www.change-pain.com/grt-change-pain-portal/GRT-CHANGE- } \\
\text { PAIN-PORTAL_Home/Useful_Tools/Patient_Tools/Pain_Assessment_Tool/206200186.jsp }\end{array}$ \\
\hline $\begin{array}{l}\text { Dartmouth-Hitchcock Norris Cotton } \\
\text { Cancer Center }\end{array}$ & http://cancer.dartmouth.edu/Global/Apps/Healthwise/media/pdf/hw/form_ty6785.pdf \\
\hline $\begin{array}{l}\text { Integrative Medicine for the } \\
\text { Underserved }\end{array}$ & http://www.im4us.org/Pain+Diaries + and+Feedback+Sheets \\
\hline Macmillan Cancer Support & http://www.macmillan.org.uk/Documents/Cancerinfo/Pain\%20diary.pdf \\
\hline MD Anderson Cancer Center & $\begin{array}{l}\text { http://www.mdanderson.org/patient-and-cancer-information/cancer-information/cancer-topics/ } \\
\text { dealing-with-cancer-treatment/pain-management/index.html }\end{array}$ \\
\hline NHS Scotland & http://www.nes.scot.nhs.uk/media/660670/chronic_pain_diary_dec_2010.pdf \\
\hline NICE & http://guidance.nice.org.uk/CG140/Publiclnfo/doc/English \\
\hline painaustralia & http://www.painaustralia.org.au/consumers/self-management.html \\
\hline Palliative Care Australia & http://www.palliativecare.org.au/Portals/46/resources/PAIN\%20MANAGEMENT\%20DIARY.pdf \\
\hline $\begin{array}{l}\text { Palliative Pain and Symptom } \\
\text { Management Consultation } \\
\text { Program }\end{array}$ & http://www.palliativecareswo.ca/MyPainDiary.pdf \\
\hline Peace Health Medical Group & http://www.hurt.com/storage/Peace\%20Health\%20Pain\%20Diary.pdf \\
\hline Psychology Tools & http://www.psychologytools.org/assets/files/Worksheets/Pain_Diary.pdf \\
\hline $\begin{array}{l}\text { Tasmanian Department of Health and } \\
\text { Human Services }\end{array}$ & http://www.dhhs.tas.gov.au/_data/assets/pdf_file/0003/36948/My_Pain_Diary_130509.pdf \\
\hline WebMD & http://img.webmd.com/dtmcms/live/webmd/consumer_assets/site_images/media/pdf/hw/form_uh1813.po \\
\hline
\end{tabular}

Abbreviations: NHS, National Health Service; NICE, National Institute for Clinical Excellence. 